\title{
Shared intention and personal intentions
}

\author{
Margaret Gilbert
}

(C) The Author(s) 2009. This article is published with open access at Springerlink.com

\begin{abstract}
This article explores the question: what is it for two or more people to intend to do something in the future? In a technical phrase, what is it for people to share an intention? Extending and refining earlier work of the author's, it argues for three criteria of adequacy for an account of shared intention (the disjunction, concurrence, and obligation criteria) and offers an account that satisfies them. According to this account, in technical terms explained in the paper, people share an intention when and only when they are jointly committed to intend as a body to do such-and-such in the future. This account is compared and contrasted with the common approach that treats shared intention as a matter of personal intentions, with particular reference to the work of Michael Bratman.
\end{abstract}

Keywords Agreements - Michael Bratman - Directed obligation ·

Joint commitment $\cdot$ Personal intentions $\cdot$ Plural subjects $\cdot$ Shared intention

\section{Introduction}

In this paper I discuss a phenomenon I shall refer to as "shared intention". I first addressed the topic in "What is it for Us to Intend?", having prepared the ground for it in On Social Facts, where my focus was on acting together and shared readiness to act. ${ }^{1}$ In later work I have amplified many aspects of the discussion. ${ }^{2}$ The present paper pulls together central elements of this material, while extending and clarifying

\footnotetext{
1 Gilbert (1997, 1989). Also Gilbert (1990).

2 For example Gilbert (2003, 2006, Chaps. 6 and 7).

M. Gilbert $(\bowtie)$

Department of Philosophy, University of California at Irvine, 625 Mesa Road, Irvine, CA 92697-4555, USA

e-mail: margaret.gilbert@uci.edu
} 
it in various ways. ${ }^{3}$ It also compares and contrasts my approach to shared intention with another, common one that treats shared intention as a matter of personal intentions, with particular attention to the work of Michael Bratman.

\section{Shared intention}

The technical phrase "shared intention", now in common use by philosophers, comes from Bratman. ${ }^{4}$ It is best to specify how I shall understand it here. As elsewhere in this paper, for the sake of simplicity I refer to an example involving two people. ${ }^{5}$

Suppose Alice asks Ben "What are you doing this afternoon?" and Ben, gesturing towards Celia, replies "We're going shopping." If Alice wereimprobably - to respond "I see: you intend to go shopping and Celia intends to go shopping", Ben might irritably reply "No, no: we intend to go shopping!" In this paper I construe the phrase "shared intention" roughly as follows: a shared intention is what people refer to when-as in Ben's case - they utter everyday sentences of the form "We intend to do A", "We're going to do A", and the like, and are not using them elliptically for "We both intend to do A" or "We all intend to do A", and so on. ${ }^{6}$ I shall refer to such sentences, when used to refer to a shared intention, as shared intention sentences.

Shared intention sentences can take a variety of forms. For example, instead of taking the form "We intend to do A" they may take the form "Our intention is to do A". They may also take the form "We intend that p" as does "We (Diane and Ed) intend that Fern attend the best school in town". I focus here on the "intend to" form of shared intention sentences.

Shared intention sentences may-explicitly or implicitly-refer to particular individuals as such as parties to the shared intention. Or they may refer to individuals insofar as they possess certain general features including relational features. Again for the sake of simplicity, my focus in this article is on the former kind of shared intention sentence, and the corresponding shared intentions. ${ }^{7}$

\footnotetext{
3 Special features of this discussion in relation to Gilbert (1997) include: an explicit focus on futuredirected shared intentions; emphasis on the problems three plausible criteria of adequacy pose for an account of shared intention in terms of corresponding personal intentions; expansion of my previous argument for the disjunction criterion; a further articulation of the obligation criterion, and further discussion of the ability of a plural subject or joint commitment account to satisfy it (see the text below for explanation of technical terms used in this note).

4 See Bratman (1993).

5 Cf. Bratman (1993). My perspective on shared intention has no problem with larger scale cases. Gilbert (2006, Chap. 8.3) discusses a broader range of phenomena but its general approach can be applied to the case of shared intention.

${ }^{6}$ Equally appropriate phrases that have been used in the literature are "collective intention" and "joint intention".

7 My perspective on shared intention can accommodate cases involving populations individuated by one or more common features, something that is necessary when dealing with what Scott Shapiro has referred to as "massively shared intentions", that is, the shared intentions of very large populations. On this see Gilbert (2006, Chap. 8.3).
} 
I am here concerned with shared intentions that regard the future, rather than shared intentions in acting. In at least some cases of future-directed intentions, whether shared or not, it is natural also to speak of plans. I take it that, indeed, if one plans to do something in the future, then one intends to do it in the sense of "intention" pertinent here. ${ }^{8}$

Intuitively an appropriate agreement between the parties is sufficient to bring a shared intention into being. Suppose that one morning Gina says to Harry "Shall we go to the library this afternoon?" and Harry replies "Sure". Without further ado, Gina might now properly say to a third party, of Harry and herself," We intend to go to the library this afternoon", in the shared intention sense of "We intend..." In at least this kind of case one might also speak in terms of planning. Thus, in the example, Gina might equally well say to the third party "We plan to go to the library this afternoon".

A future-directed shared intention may arise without an agreement between the parties. Thus Isobel may tell Jake and Kirsten to go to London together. They may exchange glances of pleasure and begin working on the details of their trip. They have a shared intention to go to London together but have never made an agreement to do so. Clearly, though understanding agreements should help us to understand shared intention, understanding shared intention is not simply a matter of understanding agreements.

\section{The personal intentions perspective}

Shared intention sentences - though completely commonplace-may seem to raise a squarely philosophical puzzle. On the face of it, one who says, for instance, "Larry and Meg intend to paint the living room tomorrow" ascribes an intention to Larry and Meg, as opposed to Larry, on the one hand, and Meg, on the other. One may think that this cannot be right-things cannot be as they seem.

One may think this because one assumes that the only intentions in the human domain are intentions of single human beings as opposed to intentions of two or more human beings, such as the putative intention of Larry and Meg. Perhaps one makes this assumption because one thinks that only a being with some feature possessed by single human beings and not possessed by two or more human beings_consciousness, perhaps, or a brain — can have intentions. In other terms, an intention must inhere in something with consciousness, or a brain. ${ }^{9}$

I shall refer to the intention of a single human being as a singularist intention. One may believe, with Wilfrid Sellars, for instance, that singularist intentions are not always personal intentions, that is, intentions expressible by sentences of the form "I intend..." One may yet think that in the human domain intentions of

\footnotetext{
8 Bratman (1987, p. 29) offers a "planning theory" intention and describes plans as "intentions writ large".

9 See e.g. Searle (1990).

10 Sellars (1963, p. 203); also Searle (1990). Both invoke intentions of individuals expressible by sentences of the form "We intend..." I have critically discussed Searle's approach to shared intention (insofar as he does approach it) in Gilbert (2007). See also (on Searle and others including Tuomela and Miller (1988)) Gilbert (1998).
} 
whatever kind are correctly ascribable only to a given individual human being. I shall call this the singularist assumption about intentions, or, for short, the singularist assumption. If the singularist assumption is true, then either shared intention sentences are false, or they are not what they seem.

The assumption itself, though, is questionable. To be sure, a singularist intention and an intention ascribable to two or more human beings - to "us" or, correlatively, "them"-will have different substrata. One can accept this without being forced to deny that the latter kind of intention is possible. Perhaps, after all, an intention need not inhere in a feature of individual human beings that "we" or "they" inevitably lack. ${ }^{11}$

In theorizing about shared intention it is best, I suggest, to set aside the singularist assumption. That leaves us with the question: how are we to understand what shared intention amounts to?

Recall that I am focusing in this paper on cases in which a shared intention is ascribed to two or more particular individuals as such. In addition, I focus on cases in which there are no pertinent authority-relations between the parties. In particular, neither is in a position to stipulate a shared intention for the two. These may or may not be the most basic cases from a genealogical point of view, but, at the least, they are commonplace cases that it is important to understand.

It is natural to proceed by asking what shared intention amounts to at the individual level. What must each of us think or have thought, and so on, in order that we intend to do such-and-such? Can a set of individually necessary and jointly sufficient conditions for a shared intention be given along these lines? In other words, can one give what I shall refer to as an account of shared intention in these terms?

It is not clear how many theorists have been concerned with shared intention in precisely my sense. ${ }^{12}$ Even when their focus is the same, they may not aim to give more than sufficient conditions for a case of shared intention, or, whatever their initial aim, they may not claim to have given more than sufficient conditions. ${ }^{13}$ Whatever precisely a given theorist's aim, one can usefully consider whether a given account of what is referred to by its author as "shared intention", "collective intention", or something with a similar flavor, does in fact constitute an account of shared intention as just characterized. That will be my procedure here.

It is standard to offer an account of shared intention in terms of a set of singularist-intentions-a set of intentions ascribed, seriatim, to different human

\footnotetext{
${ }^{11}$ For concordant discussion relating to the ascription of beliefs to two or more persons, as opposed to individual people, see Gilbert (2002a). See also Bratman (1993, p. 107).

12 Bratman (1993) opens with a reference to what I am calling shared intention sentences with the implication that these fix the topic (p. 98). To this extent we are on the same page. He then moves to the question "What do shared intentions do, what jobs do they have in our lives?" (p. 99) and couches his aim ("what we want to know") (p. 99) as that of finding an appropriate complex of the attitudes of each participant whose proper functioning would do those jobs-coordinating our personal plans and actions and providing a framework for bargaining - since "we would have reason to identify shared intention with this complex" (p. 100).

${ }^{13}$ Cf. Velleman (1997). Though clearly preferring to have developed a set of individually necessary and jointly sufficient conditions, Bratman (1993) allows that the conditions he has proposed may be sufficient but not necessary.
} 
individuals. Within this framework, a popular option is what I shall call the personal intentions perspective, according to which the singularist-intentions in question are personal intentions. This is probably the most prevalent perspective among theorists. That is hardly surprising. An appeal to personal intentions, in contrast to an appeal to any other form of singularist-intention, is an appeal to something relatively well studied and familiar from outside the philosophy of social phenomena.

Among theories that adopt a personal intentions perspective, the most prominent and influential is that of Michael Bratman. In its initial presentation in 1993 it ran roughly as follows:

With respect to a group consisting of you and me, and concerning joint activity, J, we intend to $J$ if and only if: (1) (a) I intend that we $J$ and (b) you intend that we $\mathbf{J}$; (2) I intend that we $\mathbf{J}$ in accordance with and because of (1)

(a), (1) (b), and meshing sub-plans of (1) (a), (1) (b); and you intend likewise. (3): (1) and (2) are common knowledge between us. ${ }^{14}$

Bratman proposes, then, that what our intention amounts to is a complex of, as he puts it, "interlocking" personal intentions. Since initially formulating his account Bratman has been developing a more complex set of conditions. The fundamental condition remains condition (1), which posits a set of personal intentions "that we $\mathrm{J}$ ". Other theorists working from a personal intentions perspective have offered accounts that differ in one way or another from Bratman's in its various versions.

Starting with observations on the way people think and talk about shared intention in everyday life, my own inquiries have led in a different direction. Among other things, they have suggested to me three central criteria of adequacy for an account of shared intention.

\section{The disjunction criterion}

Recall that a personal intention is understood here as an intention of a human being that is expressible by him in a sentence of the form "I intend...." Given a particular shared intention, if one party personally intends to contribute as best he can to the fulfillment of the shared intention, I shall say that he has a personal contributory intention with respect to this shared intention. I now argue that, as a conceptual matter, when two or more people share an intention, none of them need have a personal contributory intention. ${ }^{15}$

My first argument appeals to an example: an imagined retrospective report by one of the parties to a past shared intention. It should be considered, of course, without assuming the correctness of any particular account of shared intention.

The parties are Ned and Olive, and Olive is speaking: "Our plan was to hike to the top of the hill. We arrived at the hill and started up. As he told me later, Ned realized early on that it would be too much for him to go all the way to the top, and

\footnotetext{
14 This derives from the recapitulation in Bratman (1999, p. 131).

15 See also Gilbert (1997). The discussion that follows here is more extensive.
} 
decided that he would only go half way. Though he no longer had any intention of hiking to the top of the hill, he had as yet said nothing about this to me, thinking it best to wait until we were at least half way up before doing so. Before then we encountered Pam, who asked me how far we intended to go. I said that our intention was to hike to the top of the hill, as indeed it was."

I do not find Olive's report inconsistent. I conclude that people may share an intention though at least one of them lacks a personal contributory intention. I say "at least" one of them. In fact it seems that none of the parties need have such a personal intention. Thus I would not take Olive now to involve herself in an inconsistency if she went on: "As it happens, when we met Pam, I was in the same position as Ned: I'd also decided that I would not go all the way to the top of the hill, though I hadn't yet broached the subject with him."

Another argument to the same conclusion starts from a premise endorsed by Michael Bratman. He has objected to the point that an agreement can in and of itself bring a shared intention into being on the grounds that "binding agreements do not guarantee intentions on the part of the individual agents to act accordingly". 16

The quoted sentence is surely correct. But the point it makes can effectively be used to argue against the idea that one or more of the parties to a shared intention must have a personal contributory intention. For, as discussed earlier, according to a firm intuitive judgment an appropriate agreement immediately licenses the ascription of a shared intention to the parties. ${ }^{17}$

As can easily be seen, my arguments here apply not only to personal contributory intentions as defined above, but also to the different form of personal intention that figures in Michael Bratman's account of shared intention-a personal intention that we $J .^{18}$ It applies, quite generally, to any personal intention geared specifically to the satisfaction of a given shared intention.

Referring to all such personal intentions as correlative personal intentions, I propose that:

an adequate account of shared intention is such that it is not necessarily the case that for every shared intention, on that account, there be correlative personal intentions of the individual parties.

I shall call this the disjunction criterion. In what follows I assume its correctness.

Recall that I am here construing an account of shared intention as one that purports to provide individually necessary and jointly sufficient conditions on shared intention.

\footnotetext{
16 Bratman (1993, p. 111-31).

17 I write of an "appropriate" agreement because I am focusing on shared intentions to do something.

18 Bratman (101-2) points this contrast. He cites Tuomela and Miller (1988) in relation to the appeal to what I am calling personal contributory intentions. As far as I can tell, a Bratmanian intention that we $\mathrm{J}$ does not entail an intention to do one's best to achieve our J-ing. Nor does an intention that we J by means of this intention and the corresponding intention of the other party. Thus Bratman can allow that on his theory the parties to a given shared intention need not have the corresponding contributory intentions. If I am right, he still requires too much in the way of correlative personal intentions in relation to a given shared intention.
} 
Accounts in terms of correlative personal intentions of one or another kind clearly fail to satisfy the disjunction criterion. A structure of correlative personal intentions, more or less, could yet be sufficient for shared intention. The qualifier "more or less" is intended to cover such further features as the parties' knowledge of each other's personal intentions, their reliance on the other's intentions, and so on. ${ }^{19}$ This qualification should be understood in what follows. If some structure of correlative personal intentions is indeed sufficient for shared intention, then given the disjunction criterion, the hope of giving a set of individually necessary and jointly sufficient conditions on shared intention will have to be abandoned.

\section{The concurrence criterion}

Can one find a structure of correlative personal intentions that is indeed sufficient for shared intention? That one cannot is suggested by two further, plausible criteria of adequacy for an account of shared intention. I shall call these "the concurrence criterion" and "the obligation criterion". ${ }^{20}$ The naturalness of the following story can be used in support of both.

Queenie and Rom share an intention to do some shopping in a nearby town. In order to get there in time they must walk some miles along a dusty road at a certain pace. They are now half way along the road. Queenie's pace begins to slow. In a tone of mild rebuke Rom says "Can you hurry up a bit? We won't be able to get any shopping done at this rate!" Queenie says "Sorry!" and starts to move more quickly. Later she stops and for some reason announces: "That's it! I'm not going any further!" ${ }^{21}$ Rom is likely to be taken aback. Whatever he says, his thoughts may well run along these lines: "You can't just decide to stop here, not just like that!" Sotto voce or not, he might add by way of explanation: "We're on our way to the shops!" Had Queenie said something like "Do you mind if I stop here?"-seeking his concurrence in her stopping-his reaction would have been different. Then she would not have been "simply deciding" to stop.

The likelihood of such thoughts and reactions in the presence of a shared intention suggests, for one, something like the concurrence criterion:

an adequate account of shared intention will entail that, absent special background understandings, the concurrence of all parties is required in order that a given shared intention be changed or rescinded, or that a given party be released from participating in it.

I take it as read that the account should be such that the parties to the shared intention will understand that their concurrence is required as stated, and that, in addition, they will understand that this is a matter of what shared intention is. That the shared intention as such is understood to ground the need for concurrence is

\footnotetext{
19 Facundo Alonso has emphasized a form of reliance in his work on shared intention.

20 See also Gilbert (1997).

21 Perhaps, as a follower of ethnomethodologist Harold Garfinkel, she is bent on teasing out reactions to behavior she believes is "out of line".
} 
indicated by the naturalness of Rom's explanation of his "You can't just decide!' with "We're on our way to the shops!" This presents itself, indeed, as a complete explanation of the need for concurrence.

The qualifier "absent special background understandings" is important, and should also be taken as read in what follows. It allows that prior agreements such as the following are possible. Queenie is not sure she wants to walk all the way into town that afternoon, so before she and Rom set out on their shopping expedition she gets him to agree in advance that if at any time she feels like stopping, she is free to do so. Against this background, Rom would not react as in the original story. For now, given their agreement, Queenie can just decide, "just like that". The qualification is crucial: Rom can be considered to have concurred in advance with any proposal from Queenie that she not go all the way into town. ${ }^{22}$

The concurrence criterion in effect spells out the most plausible interpretation of Rom's "You can't just decide!" He means that Queenie is not in a position unilaterally to decide to stop where she does-not without coming up against their shared intention. What is required to render her action faultless in the relevant respect is Rom's concurrence.

One can of course make a personal decision not to act in accordance with a shared intention; this is what Queenie does in the initial story. It is also what Ned does in the story of his shared intention with Olive to hike to the top of the hill. What neither Queenie nor Ned is in a position unilaterally to do by virtue of his or her own decision, in and of itself, is change, rescind, or release themselves from participation in the pertinent shared intention in such a way as to make faultless their acting contrary to it.

I shall now assume that the concurrence criterion must indeed be satisfied by an adequate account of shared intention. ${ }^{23}$ Given that criterion, there is another significant problem for the personal intentions perspective.

One is a position unilaterally to rescind one's personal intentions. One is also in a position unilaterally to alter them with respect to some detail. One can "just decide" to do so, and it is done. Thus, though one might beg someone else not to change his mind, point out some undesired consequence of his doing so, malign him for doing so, and the like, it is not true as a matter of what a personal intention is that he is not in a position to do it without one's concurrence.

It follows that the concurrence criterion has a sharper edge than the disjunction criterion. According to the latter, there need be no correlative personal intentions given a shared intention. This leaves open the possibility that some structure of personal intentions is sufficient for shared intention. Given the concurrence criterion, however, it is hard to see that such a structure can be sufficient for shared intention. If a shared intention is such that one cannot unilaterally release oneself from its constraints or change its details by a simple change of mind, there must be something other than a structure of personal intentions at its core. For given any

\footnotetext{
22 A reader may be reminded of the duet-singers in Bratman (1993), to whom I recur later. Bratman's example is pertinent to both criteria though not, I think, adversely. For an extended discussion of background understandings of the kind in question here, see Gilbert (2006, Chap. 6).

23 There is a much longer pertinent discussion of a similar concurrence condition with respect to joint activity (as opposed to shared intention) in Gilbert (2006, Chap. 7); see also Gilbert (1997).
} 
personal intention, the person with that intention is in a position to rescind it or change its details at will. When such an intention is constitutive of a shared intention, to rescind or change it is to demolish the shared intention itself.

\section{The obligation criterion}

Going back now to the story of Rom and Queenie's shopping expedition, when Rom says, "Can you hurry up a bit? We won't be able to get any shopping done at this rate!" he both mildly rebukes Queenie for slowing down, and implicitly demands that she hurry. Her "Sorry!" presupposes his standing to issue this rebuke and this demand.

This suggests something like the following obligation criterion:

an adequate account of shared intention will entail that each party to a shared intention is obligated to each to act as appropriate to the shared intention in conjunction with the rest.

I take it as read here that the account should be such that the parties to the shared intention will understand that they have the stated obligations, and that they understand that this is so as a matter of what a shared intention is. A defense of the last point can be made in similar terms to that offered in relation to the parallel point about the concurrence criterion.

For brevity's sake, in referring to the obligations covered by this criterion I may refer to a given party's having an obligation to conform to the shared intention. One can, of course, fail to satisfy these obligations: their existence is not disproved by such failure.

The obligation criterion, as just set out, concerns obligations of a particular type. Thus each party is said to be obligated to the other parties to do something. I shall refer to obligations of this type as directed obligations, using an established phrase that is appropriate here. Before I say why the criterion is couched in these terms, it will be helpful to say more about directed obligations.

Rights theorists commonly use the language of directed obligation: A's right against B to an action of B's is said to be equivalent to B's obligation to A to perform the action. The word "duty" is often substituted for "obligation" in this formulation. Rights of the kind in question are generally known as claim-rights. It might be thought that in order to understand better the nature of directed duties one can simply reach into the theory of claim-rights for an answer. There is great controversy among rights theorists, however, as to what a claim-right amounts to. The same goes, not surprisingly, for the nature of directed obligations.

As to the latter, as far as the theory of shared intention goes, I would argue that the interpretation we need is in terms of owing, an interpretation given by two distinguished rights theorists, H. L. A. Hart and Joel Feinberg. ${ }^{24}$ In this construal, the parties owe each other action appropriate to the shared intention. To say that, however, is not to conclude discussion. People use the term "owe" in different

\footnotetext{
${ }^{24}$ See Hart (1955), Feinberg (1970).
} 
ways, not always in a way that is appropriate here. For instance, you may say "I owe him a favor" without meaning that he has a right to a favor from you.

Feinberg refers at one point to a right-holder's demanding what he has a right to as his. ${ }^{25}$ This implies that if I owe someone a certain action, in the sense of "owe" in question here, he already in some intuitive sense owns that action. On hearing this one may wonder if it can be correct. In what sense can one own the future action of another person? I believe that something can be made of it, as I explain later. For now I explain how some pertinent and important intuitive ideas in addition to those of owing and claim-rights fit together with the idea of one's owning, in some intuitive sense, another's action.

Feinberg refers to a right-holder's demanding something as his. I take this to offer us a plausible way to amplify the nature of a demand, or, if you like, a demand that is something more than a seriously intended imperative. Anyone is in a position to address such an imperative to anyone else. Indeed, if one issues such an imperative while threatening some undesired consequence if its addressee does not conform to it-for example, if one is brandishing a gun while saying "Hand over your money!" - one is likely to be successful in obtaining such conformity. For a demand in the sense in question here one needs a special standing. The same goes for the issuing of a rebuke, which might be thought of as a retrospective demand. ${ }^{26}$

I take from Feinberg the point that to be in a position to demand something from someone is for it already to be in some intuitive sense one's own. That is because demanding in the relevant sense is demanding as one's own. This, Feinberg implies, is something any claim-right holder can do with respect to an action to which he has a right.

This suggests that there is an important and closely linked family of concepts here: the concept of a right to some future action of the right's addressee, one's current ownership, in some intuitive sense, of that action, one's being owed that action by the right's addressee prior to his performing it, one's being in a position to demand it of him prior to its performance, and one's being in a position to rebuke him if he has failed to perform it at the appropriate time. The linkage can be displayed as follows: one who has a right to someone's future action already owns that action in some intuitive sense of "own". Until the action is performed he is owed that action by the person concerned, thus being in a position to demand it of him prior to its being performed and to rebuke him if it is not performed. If it is performed, it has finally come into the possession of the right-holder, in the only way that it can.

This all suggests a way of interpreting the obligation criterion that fits the observable facts about shared intention and offers a plausible interpretation of them. Consider again the case of Rom and Queenie. Rom both rebukes Queenie (albeit mildly) for going too slowly for the satisfaction of their shared intention, and demands that she speed up if she can. Queenie implicitly accepts his standing to issue such rebukes and demands when she says "Sorry!" In so doing she acknowledges, in effect, that at the time he spoke Rom had a right against her to

\footnotetext{
${ }^{25}$ See Feinberg (1970).

${ }^{26}$ See also Gilbert (2006, Chap. 1).
} 
actions in accordance with the shared intention; and that she owed him such actions, which he already in some sense owned. In other terms, she has the corresponding directed obligation to perform such actions. Intuitively the same goes, with appropriate changes, for the parties to any shared intention.

One who accepts the obligation criterion so interpreted-as I shall in what follows - could also posit as a criterion of adequacy a "standing to demand" criterion and a correlative "standing to rebuke" criterion. This is redundant, strictly speaking, once one has clarified the nature of the obligation at issue in the way just indicated. If you owe me your action in the sense implying that I already in some sense own it, I am in a position to demand that action as mine and to rebuke you when you fail to perform it.

Standing, incidentally, must be sharply distinguished from justification. One may have the standing to demand something of someone, yet not be justified in doing so, in the circumstances. Thus were Queenie so sensitive to criticism that she would suffer a grave physical crisis if rebuked, in most circumstances it would be wrong to rebuke her even if one had the standing to do so.

There are various ways in which the obligation criterion might be satisfied. An account of shared intention could list one or more other conditions from which the pertinent obligations of the parties did not follow and then explicitly posit, in addition, the existence of such obligations. That would be unsatisfactory because it would not explain the ground of the obligations. More desirable would be an account such that the conditions it explicitly posits-without explicitly positing the obligations-are such that it follows from them that the parties have these obligations. That way, the obligations would be explicable on the basis of the other conditions. That would fit well with a point made earlier: one who calls another on his inappropriate action may well justify his intervention by reference simply to the shared intention as such.

The obligation criterion, like the concurrence criterion, argues against the sufficiency of an account of shared intention in terms of correlative personal intentions. For, though my personal intention constrains my behavior, it does not in and of itself entail that I owe you the intended action.

Michael Bratman has allowed that when there is a shared intention in his sense, there are not necessarily any mutual obligations of the parties. He has also argued, in effect, against the obligation criterion. I briefly review and respond to three of those arguments here. ${ }^{27}$

One argument involves the example of two duet-singers who "each value their duet-singing but nevertheless have a clear understanding between them that neither is making any binding promise to or agreement with the other concerning their singing. Each publicly states that she reserves the right to change her mind". ${ }^{28}$ There are various ways of construing this example. If we give the most natural reading to "their duet-singing" we should allow that these singers do have an established shared intention. At the same time we can construe their "clear understanding" as a side-agreement to the effect that each may proceed as if they

\footnotetext{
${ }^{27}$ In doing so I focus on material that was published prior to the completion of this paper.

28 See Bratman (1993, p. 111).
} 
have no obligations to one another with respect to their duet-singing. The possibility of such a side-agreement does not force us to reject the obligation criterion. A similar point was made earlier in relation to the concurrence criterion. $^{29}$

Another argument alludes to a case involving coercion. Here is a version that best fits the present juncture in my own discussion. Without any warrant but my own desire, I tell you that unless you agree to play tennis with me tomorrow, I will blow up your house. Sincerely intending to bring into being the appropriate shared intention, you reply, "Okay, let's do it!" Of this type of scenario Bratman says "it seems to me that in this case I have no entitlement to your playing your part". 30

I agree with Bratman that a shared intention can be established in such circumstances. I suggest, however, that once it has been established in the way described, you will understand that you owe me actions consistent with it. This may lead you to act accordingly. Perhaps, though, you will judge that all things considered it is rationally permissible for you not to do so, and hence fail to show up for tennis on the day in question. You may also think that all things considered it is impermissible for me to rebuke you on that account. Yet you are likely to accept my standing to rebuke you for failing to act consistently with our intention.

It is quite possible-likely, in fact - that Bratman is thinking of entitlements of a specific kind, and that the parties to a shared intention have rights against each other of another kind. Then his judgment on this case could be correct in its own terms, but it would not tell the whole story about shared intention and obligation. ${ }^{31}$

Another argument alludes to shared intentions to do something bad. Bratman assumes that these cannot involve obligations to act in favor of the shared intention. $^{32}$ Yet those who share intentions to do bad things may well think otherwise; and, as in the previous case, it is possible that Bratman's negative conclusion is valid only for a kind of obligation other than that involved in shared intention. I return to this issue later.

Though inclined to reject the obligation criterion, Bratman allows that the parties to a shared intention according to his account often have obligations to one another to act in favor of the shared intention. This could be due to prior agreements or promises. Or it may be due to factors downstream from the shared intentionperhaps not very far downstream-which trigger a moral principle such as the one argued by Thomas Scanlon to explain the moral wrong involved in promisebreaking, but not that alone, a principle he dubs "Principle F". 33

All this may well be true. Allowing for the sake of argument that it is, it cannot be the whole story of the obligations associated with shared intention. As Bratman

\footnotetext{
29 See also Gilbert (2000, p. 35-36).

30 See Bratman (1999, Chap. 7, pp. 132-133).

31 I discuss the related case of coerced agreements at length in Gilbert (1996, Chap. 12). See also Gilbert (2006).

32 See Bratman (1999, Chap. 7, p. 132-6). Others have had this reaction in related contexts. For discussion of the related case of immoral agreements (along with case of coerced agreements) see Gilbert (2006).

33 "F" stands for "fidelity". Since the details of this complex principle are not of central importance here I do not quote it. See e.g. Scanlon (1998).
} 
would allow, shared intentions can arise without a background agreement or promise. Yet, as argued earlier in relation to the example of Queenie and Rom, a shared intention is understood in and of itself to suffice for the obligations in question.

What of downstream factors such as expectations and reliance, coupled with Scanlon's Principle F, or something like it? Since these are indeed downstream factors they cannot accommodate the intuition that obligations inhere in the shared intention.

There is, in any case another problem with this move. As I have argued elsewhere, the application of a principle such as Scanlon's Principle F to a given party does not show that the other party has a claim-right against him, along with the standing to demand as his what he has a right to. Rather, it shows that the first party is morally required to act in favor of the shared intention, subject perhaps to certain conditions. ${ }^{34}$

\section{The plural subject account of shared intention}

As I explain, the account I have been developing respects the disjunction, concurrence and obligation criteria. I first present the account without explanation. In its most general form it runs thus:

Members of some population $\mathrm{P}$ share an intention to do A if and only if they are jointly committed to intend as a body to do A.

For cases of the type on which I have been focusing in this paper it would run, more specifically, thus:

Persons X, Y, and whatever particular others share an intention to do A if and only if $\mathrm{X}, \mathrm{Y}$, and these particular others are jointly committed to intend as a body to do A.

I must now explain what it is for people to be jointly committed in some way and what it is to intend as a body to do A. I start with joint commitment.

The relevant concept of commitment can usefully be introduced, albeit roughly and briefly, by reference to personal intentions and decisions, since people are committed by them in the appropriate sense. I take it that given either a standing, unrescinded decision or a current intention, the person in question has sufficient reason to act in a particular way even without this having been the case prior to the formation of the intention or decision. In saying that one has sufficient reason to act in some way I mean that, if all else is equal, one ought so to act. The "ought" here is a matter of what might be referred to as rational requirement. The point is that one

\footnotetext{
${ }^{34}$ I argue at length that Principle F, in particular, does not suffice to explain the rights of promisees, in particular, in Gilbert (2004). I also raise doubts there about the sufficiency for this purpose of moral principles more generally. In the case of an application of Principle F specifically, the condition that needs to hold is that the second party does not say it is fine with him that the first party not act in favor of the shared intention. See Gilbert (2004) on unhelpfulness of this clause in explaining the rights of a promisee.
} 
is not being appropriately responsive to the considerations that bear on the case if one fails to act as one ought. ${ }^{35}$

Sometimes, I take it, all else is not equal. That is, all things considered, I ought not to do A, in spite of my decision or intention to do it. Perhaps doing A is imprudent or immoral. ${ }^{36}$ Then, all things considered, I ought not to do A.

I do not mean to imply that either decisions or intentions are "reasons" in a particular sense of "reason" on which many contemporary philosophers have focused. Such reasons are, we might say, considerations for and against a particular action that would appropriately be weighed prior to making a decision whether or not to perform it.

Personal decisions and intentions create commitments of a kind I shall call personal commitments. For present purposes the key salient feature of such commitments is that the one who personally formed or made the corresponding personal decision or intention is in a position unilaterally to expunge them as a matter of personal choice.

A joint commitment is not a concatenation of personal commitments. Thus it is not formed by virtue of the formation of a personal commitment by each of the parties. In particular, as I have emphasized elsewhere, its formation is not achieved by the expression of a conditional personal commitment which is met by a clinching expression from the other party or parties. ${ }^{37}$

How, then, is a joint commitment created? In the basic case, on which I focus here, each of two or more people must openly express his personal readiness jointly with the others to commit them all in a certain way. ${ }^{38}$ I mean to imply that each is indeed personally ready for this, and that he expresses this readiness. ${ }^{39}$ Once the concordant expressions of all have occurred and are common knowledge between the parties, the joint commitment is in place.

There is doubtless more than one way further to articulate the idea of a joint commitment to intend as a body to do something. One way keeps the word "body" in play: roughly, the parties are jointly committed as far as possible to emulate, by virtue of the actions of each, a single body that intends to do the thing in question. Here speech and deliberate inaction are understood to be included under "actions". More briefly: the parties are jointly committed to emulate a single body with a certain intention. I take it that whereas a single human being constitutes a single body, in the sense I have in mind, a plurality of human individuals does not and

\footnotetext{
$\overline{35}$ For concordant discussion see Verbeek (2007).

36 Even if all else is not equal, so that one ought not to act in accord with one's decision all things considered, I take it that something is amiss if one fails to change one's mind yet acts contrary to the decision. This could happen if one simply forgets one's decision and goes ahead and acts contrary to itwithout explicitly changing one's mind. I shall not pursue this aspect of the matter here, though I take it to be significant.

37 Some tentative formulations in Gilbert (1989) may have led to misunderstanding in this respect; though see e.g. p. 282, which attempts to forestall such misunderstandings. The position involving conditional personal commitments criticized in Roth (2004), then, is not mine. See Gilbert (2003) for more discussion on this point.

38 Non-basic cases involve authorities whose status derives from a basic joint commitment. See Gilbert (2006, Chaps. 7, 9).

39 In Gilbert (1989, Chap. 4) I argue for an "expressed" condition as well as an "expression" condition.
} 
cannot constitute such a body. At least to some extent, however, such a plurality can emulate such a body. ${ }^{40}$

One does not have to use the term "body" in one's further articulation of the idea of a joint commitment to intend as a body to do something. One might refer to a single person, for instance, or agent. Another possibility is something along the following lines: a joint commitment to intend as a body to do something is a joint commitment as far as possible to produce, by virtue of the actions of each, a single instance of intending to do that thing.

As to what precisely is intended, we need a felicitous way to deal with the fact that some of the things we may share an intention to do are designed for two or more participants - things such as playing a duet or a game of basketball or tennis-and some are not so designed. For instance, we may intend to prepare a meal, solve a problem and go for a walk.

Consider a case of the latter kind. Sally and Tim share an intention to go for a walk. Understanding what it is to intend as a body along one of the lines suggested, we might articulate their situation as a whole roughly as follows: Sally and Tim are jointly committed to intend as a body to produce, by virtue of the actions of each, $a$ single instance of going for a walk with the two of them as the participants in that walk. One can expect this spare and basic idea to be filled out in concrete situations by background social conventions or explicit agreements between the parties as to how a walk for two is to proceed.

Now consider a case of the other kind: Sally and Tim intend to play a game of tennis. This can be understood in a parallel way, roughly as follows: Sally and Tim are jointly committed to intend as a body to produce, by virtue of the actions of each, a single instance of a tennis game with the two of them as the sole participants in that game.

The expressions of personal readiness necessary for the creation of a joint commitment can take various forms. Some may amount to the making of a verbal agreement as in: "Shall we go to London together?" "Okay!" Indeed, one can argue that an agreement is a joint decision, where people make such a decision by explicitly proposing and accepting a particular plan of action, thus becoming jointly committed to endorsing as a body that plan. ${ }^{41}$ Given this construal, the parties to the example agreement are jointly committed to intend as a body to go to London together. Thus the plural subject account of shared intention accommodates well the intuitive judgment that an appropriate agreement immediately gives rise to a shared intention.

A less explicit process is also possible. ${ }^{42}$ This may be considerably extended in time. Then, what emerges will not be a joint decision, specifically, but will simply be a jointly commitment to intend as a body to do something.

\footnotetext{
${ }_{40}$ To the extent that the parties can emulate such a body, and only to that extent, they can constitute one. In the past I have sometimes written of the parties being committed to "constitute as far as possible a single body that does such-and-such". I think an appeal to emulation is more helpful, though the other characterization can stand if understood as just indicated.

${ }^{41}$ Cf. Gilbert (2006, p. Chap. 10); also Gilbert (1996, Chap. 13). In the text here I emphasize the involvement of an explicit process in the making of an agreement.

${ }^{42}$ For examples in the context of a discussion of joint commitment generally see, e.g., Gilbert (2006, Chap. 7).
} 
Like a personal commitment, a joint commitment can only be rescinded by the "one" who created it; in this case, absent special background understandings, that "one" comprises those who jointly committed themselves by their concordant expressions. Together they constitute the creator of the commitment; the "one" who imposed the relevant normative constraint on each of the parties. ${ }^{43}$

There can be joint commitments not only to intend as a body to do something but also to believe as a body that such-and such, to accept as a body a certain rule, and so on. In earlier writings I have labeled those who are jointly committed with one another in some way a "plural subject". This label should not be thought to have any ontological implications beyond those involved in the claim that certain persons are jointly committed in some way.

Given the meaning of my technical phrase "plural subject" I dub the account of shared intention I am discussing the plural subject account of shared intention. Though its ontological commitments are, I believe, unexceptionable, it does imply that a shared intention is not constructed out of singularist-intentions, contrary to the assumption of many.

Elsewhere I have offered independent arguments for the thesis that the concept of joint commitment just sketched lies at the foundation of many central everyday concepts including those of a group's belief, a social convention, and a group's language. ${ }^{44}$ Its invocation as part of an account of shared intention, then, is by no means ad hoc. On the contrary, one reason for my initially proposing a plural subject account of shared intention was my prior recognition of the plausibility of such an account for other central social phenomena.

\section{Implications of the account}

I now justify my claim that the plural subject account of shared intention meets the criteria of adequacy mentioned. As to the disjunction criterion, since a shared intention (according to the account) is a matter of joint commitment, it is logically possible for it to exist in the absence of correlative personal intentions of the participants. So that criterion is satisfied.

What parties to a shared intention cannot do is alter or rescind the foundational joint commitment without the concurrence of the other parties, absent special background understandings. That latter point shows that the concurrence condition is satisfied.

I now argue that the obligation criterion is satisfied by the plural subject account. Recall this criterion: on the proposed account of shared intention the participants must owe one another future conforming actions, where that means that they already in some intuitive sense own these actions in advance of their performance. Crucially, in co-creating their joint commitment the parties together impose on each

\footnotetext{
43 With respect to the ending of a joint commitment arrived at without an agreement it may be more apt to speak of something other than "rescission", which conjures a focused, dated process, with respect to its demise. See Gilbert (2006, pp. 141-143).

44 In Gilbert (1989) with amplifications and further points made elsewhere. See Gilbert (1997) for a summary of the framework of analysis that has evolved therefrom.
} 
other a constraint such that, all else being equal, a given party will not act as he ought should he fail to respect it. When this occurs one can say that the parties have together "put their dibs" on the future conforming actions of each one, and to that extent have made them their own. Thus a given party is in a position to demand conformity or rebuke for non-conformity as co-owner of the action in question. Making things explicit, he might say "Give me that, it's mine-qua one of us!"

I take it that if A owns B's action in the intuitive sense now in question, that suffices to make it the case that prior to its performance B owes A the action. I here waive the question whether there is any other intuitive sense of owning an action such that one's owning it in that sense implies that prior to performance one is owed that action.

The foregoing line of argument is a matter of the authorship of the commitment and its constraining nature. The obligations of the parties are, one might say, purely internal to the joint commitment. They exist whenever a joint commitment is made. $^{45}$

On the face of it, it is possible for people jointly to commit one another to intend as a body to do something that considered in itself, apart from that commitment, is morally impermissible — something that is, for short, an evil act. ${ }^{46}$ In saying this I do not mean that the action in question is seen by the parties as evil but that it is in fact evil. I shall assume for present purposes that such a joint commitment is indeed possible. $^{47}$

Suppose, then, that Ulrich and Vance share an intention according to the plural subject account to do some evil thing. By the above argument, each will then owe the other actions that conform to the constitutive joint commitment, though neither (I shall assume) ought to conform to it all things considered. In other terms, they will be obligated to each other to conform, though neither ought to conform all things considered.

One may now be moved to say that there is a problem here for the plural subject account precisely because it implies that the parties to a shared intention to do evil are obligated in this way. That, one may say, cannot be the case. In saying this, one may well have in mind a type of obligation that is not here to the point. ${ }^{48}$ In particular, one may have in mind the obligations that accrue to those who fall under a moral principle such as Scanlon's principle F. Call an obligation of this type a moral requirement. If one has a shared intention to do $\mathrm{A}$, where $\mathrm{A}$ is an evil action in the sense at issue, then in my view all else being equal it is not the case that one is morally required, or obligated in that way, to conform to the constitutive joint

\footnotetext{
45 Though I prefer the line of argument presented here, I have argued for the "internally" obligating nature of joint commitment in other ways also. See Gilbert (2000, Chap. 4).

${ }^{46}$ I do not mean here to plump for some kind of deontological as opposed to consequentialist ethics. If you like read "morally impermissible" as "morally impermissible in normal circumstances", and read the rest of the discussion as assuming normal circumstances.

47 Any argument to the effect that it is not would most likely imply that a personal commitment to do what is in fact evil is impossible also. Both positions are on the face of it implausible.

${ }^{48}$ For some discussion of so-called obligations as a genus and at least two significantly different species of so-called obligation see Gilbert (2006, Chaps. 2, 7, and elsewhere).
} 
commitment. Clearly, moral requirements and the directed obligations of joint commitment differ radically in character. ${ }^{49}$

\section{The plural subject account and personal intentions}

According to Bratman, if we two share an intention to paint the house together, for instance, then each of us personally intends that we paint the house together, and so on. In my terms, each is then personally committed to act in accordance with his personal intention. On the plural subject account the individual parties to a shared intention are necessarily committed in related ways. The commitments in question, however, are not personal commitments but rather what one might refer to as "individual" commitments. 50

Thus suppose that Will and Xenia have a shared intention according to the plural subject account. If he proposes a shared sub-plan to her, and it is reasonable, there is already some onus on her to accept it, as a party to the fundamental joint commitment: she is already committed not capriciously to reject Will's proposal, an individual commitment deriving from the fundamental joint commitment of the two. The same goes for Will, of course, with relevant changes.

Xenia cannot unilaterally revise or rescind the joint commitment from which her individual commitment derives, nor can she release herself from it. Thus her being subject to the derived individual commitment, also, is dependent on more than her own will and pleasure. This is not true of the personal commitments deriving from a personal intention, since the person with the intention is in a position unilaterally to revise or rescind it.

Given this difference, the derived commitments involved in shared intention on the plural subject account have a greater stability in terms of revisability and rescindability than both the derived and non-derived commitments involved in any personal intentions account.

There is also more reason to conform to a joint commitment, as such, than there is to a personal intention that is part of a Bratmanian complex of interlocking personal intentions as such. As he will understand, each party owes every other conformity to a joint commitment, and, because of this, each has the standing to make demands and issue rebukes in relation to threatened or actual non-conformity of a given party.

In addition to the individual commitments derived from the joint commitment at the heart of a given shared intention, on the plural subject account, the parties are likely to develop a variety of concordant personal intentions. These will arise under the guidance, so to speak, of the foundational joint commitment and the joint commitments involved in any shared sub-plans, along with individual commitments derived from these. For instance, if Will and Xenia now share the sub-plan he proposed, and it involves his getting paint at the store, he may form the personal intention to go to the garage and start the car, as a means of fulfilling his individual commitment to go to the store.

\footnotetext{
49 See Gilbert (1996, Chap. 7, 2006, Chap. 7).

50 See Gilbert (1996, pp. 11-13) for a detailed treatment of these "individual" commitments. See also Gilbert (2003) and the text below.
} 
Though the plural subject account does not itself posit any particular personal intentions, then, one can predict that shared intentions on that account will be accompanied by a variety of meshing personal intentions of the parties, when those parties act appropriately in light of their shared intention and any shared sub-plans they have consequently developed.

It is worth emphasizing that in saying this I am not allowing that when there is a shared intention according to the plural subject account one can predict the presence of personal intentions of the type at the core of Bratman's account, that is, personal intentions "that we J". Nor am I saying that the development of correlative personal intentions in the sense defined earlier is predictable. On the contrary, any need for commitment in that respect is already taken care of by the joint commitment at the core of the shared intention. The personal intentions that are needed, and hence predictable, are intentions to act in ways concordant with the shared intention, though the content of the shared intention itself does not implicitly specify them.

Given the plural subject account, then, shared intentions are apt to play important roles emphasized by Michael Bratman as roles we understand shared intention to play, in advance of our development of an account of it. ${ }^{51}$ In particular, they help to organize and coordinate our personal intentions and plans in ways that favor the fulfillment of the shared intention. They do this in part by providing a stable framework within which bargaining and negotiation about how things are to proceed may take place.

Bratman has argued, reasonably, that the structure of personal intentions described in his account of shared intention plays these roles. It is important to note, however, that shared intentions on the plural subject account are even better suited to play them. Shared intentions on the plural subject account are a more felicitous, because more stable framework for bargaining and negotiation and, relatedly, a more felicitous means of coordinating the personal intentions of individuals, and keeping them on the track of the shared intention.

Suppose, then, that one were to agree with Bratman when he says:

Can we describe an appropriate complex from whose proper functioning would emerge the coordinated action and planning, and the relevant framework for bargaining, characteristic of shared intention? If so, we would have reason to identify shared intention with this complex. ${ }^{52}$

Set aside his assumption that there is a "complex" in question that is a matter of the "attitudes of each of the individual agents-attitudes that have appropriate contents and are interrelated in appropriate ways", which may or may not rule out the conditions stipulated by the plural subject account. Think of the term "complex" as referring simply to a number of factors, possibly just one. One could then argue that since when functioning properly the plural subject complex is more efficacious in the pertinent way than a personal intentions complex-however complicated-it has a better title to be identified with shared intention.

\footnotetext{
51 See Bratman (1993, p. 99).

52 This and the following quotation come from Bratman (1993, p. 100).
} 
If we allow that the tendency of shared intentions to fulfill the roles mentioned by Bratman can reasonably be invoked in a full set of criteria of adequacy for shared intention, we must also allow that such a full set will include others that the personal intentions perspective is harder put to it to satisfy, even up to a point. In particular it will include the disjunction, concurrence, and obligation criteria roughly specified earlier.

Though it is not necessary for an adequate account of shared intention that shared intentions on that account possess features that have been highlighted by theorists as features of personal intentions, it is certainly of interest to consider whether shared intention on a given account possesses such features. ${ }^{53}$

Bratman considers this question in relation to his own account of shared intention and gives a positive answer. One should also give a positive answer with respect to the plural subject account. Consider the following important features of intentions at the personal level emphasized by Bratman, here described somewhat cursorily: personal intentions are relatively stable states of their possessors and are subject to norms of coherence and consistency both synchronic and diachronic. ${ }^{54}$ Shared intentions according to the plural subject account are relatively stable, and they would appear to be subject to similar norms of consistency and coherence.

\section{Concluding remarks}

I have proposed three main criteria of adequacy for an account of shared intention, along with several subsidiary criteria. The plural subject account satisfies these criteria. Something that I shall not pursue here is a conjecture that I am inclined to accept: if and only if we invoke joint commitment in one way or another are we in a position to develop an account of shared intention that meets these criteria. Certainly, an account of shared intention whose core is a structure of correlative personal intentions does not seem capable of satisfying any of these criteria.

Whether or not it stands as the most adequate account of shared intention it is worth having in view a joint commitment account along the lines I have proposed. For whatever we call a situation in which the conditions it stipulates obtain, that situation is likely to be of great consequence for all concerned. This is true, indeed, of any situation in which there is a joint commitment, in which sociality and an important form of obligation come together. Whatever we jointly commit ourselves to "do" as a body-decide, intend, believe, accept as a rule, and so on-we create for each one of us a relatively intractable, and hence relatively stable framework for his or her life, both in the short and in the longer term. ${ }^{55}$

\footnotetext{
53 Cf. Gilbert (2002a) in relation to belief, where points supposedly criterial for belief in the individual case are explored in relation to the collective case.

54 Cf. Bratman (1993, p. 101).

55 A longer version of this paper entitled "Two Approaches to Shared Intention: An Essay in the Philosophy of Social Phenomena" will appear in an anniversary issue of Analyse und Kritik (2009). I am grateful to the editor of that journal, Anton Leist, for permission to publish this version in Philosophical Studies, and for comments on the longer version, also to two anonymous referees. Warm thanks also to Abe Roth, Thomas Smith, and Frank Stewart for comments on a draft, to Michael Bratman for his participation in our long and continuing dialog on shared intention, and to Mark Wrathall, editor of this volume of Philosophical Studies.
} 
Open Access This article is distributed under the terms of the Creative Commons Attribution Noncommercial License which permits any noncommercial use, distribution, and reproduction in any medium, provided the original author(s) and source are credited.

\section{References}

Bratman, M. (1987). Intentions, plans, and practical reason. Cambridge, MA: Harvard University Press. Bratman, M. (1992). Shared cooperative activity. Philosophical Review, 101, 327-340.

Bratman, M. (1993). Shared intention. Ethics, 104, 97-113.

Bratman, M. (1999). Faces of intention. Cambridge: Cambridge University Press.

Feinberg, J. (1970). The nature and value of rights. Journal of Value Inquiry, 4, 243-257.

Gilbert, M. (1987). Modeling collective belief. Synthese, 73, 185-204. Reprinted in Gilbert (1996).

Gilbert, M. (1989). On social facts. London: Routledge and Kegan Paul.

Gilbert, M. (1990). Walking together: A paradigmatic social phenomenon. Midwest Studies in Philosophy, 25, 1-14. (Reprinted in Gilbert (1996)).

Gilbert, M. (1996). Living together: Rationality, sociality, and obligation. Lanham, MD: Rowman and Littlefleld.

Gilbert, M. (1997). What is it for Us to Intend? In G. Holmstrom-Hintikka \& R. Tuomela (Eds.), Contemporary action theory, (Vol. 2, pp. 65-85). Dordrecht. (Reprinted in Gilbert (2000)).

Gilbert, M. (1998). In search of sociality: Recent developments in the philosophy of social phenomena. Philosophical Explorations, 1, 233-241. (Reprinted in Gilbert (2000)).

Gilbert, M. (2000). Sociality and responsibility: New essays in plural subject theory. Lanham, MD: Rowman and Littlefield.

Gilbert, M. (2002a). Belief and acceptance as features of groups. Protosociology, 16, 35-69.

Gilbert, M. (2002b). Collective wrongdoing: Moral and legal responses. Social Theory and Practice, 28, 167-187.

Gilbert, M. (2003). The structure of the social atom: Joint commitment as the foundation of human social behavior. In F. Schmitt (Ed.), Socializing metaphysics (pp. 39-64). Lanham, MD: Rowman and Littlefield.

Gilbert, M. (2004). Scanlon on promissory obligation: The problem of promisees' rights. Journal of Philosophy, 101, 83-109.

Gilbert, M. (2006). A theory of political obligation: Membership, commitment, and the bonds of society. Oxford: Oxford University Press.

Gilbert, M. (2007). Searle and collective intentions. In S. Tsohatzidis (Ed.), Intentional acts and institutional facts. Dordrecht: Springer.

Gilbert, M. (2008). Social convention revisited. Topoi, 27, 5-16.

Hart, H. L. A. (1955). Are there any natural rights? The Philosophical Review, 64, 175-191.

Roth, A. S. (2004). Shared agency and contralateral commitments. Philosophical Review, 113, 359-410.

Scanlon, T. (1998). What we owe to each other. Cambridge, MA: Harvard University Press.

Searle, J. (1990). Collective intentions and actions. In P. R. Cohen, J. Morgan, \& M. E. Pollack (Eds.), Intentions in communication (pp. 401-415). Cambridge, MA: MIT Press.

Sellars, W. (1963). Imperatives, intentions, and the logic of 'Ought'. In G. Nakhnikian \& H.-N. Castaneda (Eds.), Morality and the language of conduct (pp. 159-218). Detroit: Wayne State University Press.

Tuomela, R., \& Miller, K. (1988). We-Intentions. Philosophical Studies, 53, 367-389.

Velleman, D. (1997). How to share an intention. Philosophy and Phenomenological Research, 57, $29-50$.

Verbeek, B. (2007). Rational self-commitment. In F. Peter \& H.-B. Schmid (Eds.), Rationality and commitment. Oxford: Oxford Universty Press. 